\title{
Causas da variabilidade do tempo de execução dos processos em diferentes sistemas construtivos
}

\author{
Causes of variability in the execution time of processes in \\ different construction systems
}

\section{Herbert Melo Cruz \\ Débora de Gois Santos \\ Ludmilson Abritta Mendes}

\section{Resumo \\ $\mathbf{U}$}

m dos grandes desafios para o gerenciamento da construção é a execução das atividades de acordo com as durações programadas, sendo comum a ocorrência de variabilidade. $O$ objetivo desta pesquisa foi analisar as causas da variabilidade do tempo de execução dos processos em diferentes sistemas construtivos, classificando-as em níveis de risco. A metodologia consistiu em um estudo de casos múltiplos em diferentes sistemas construtivos, sendo aplicado com diversos trabalhadores de obras um questionário com 31 causas de variabilidade divididas em oito categorias. Visou-se levantar as variáveis frequência e intensidade de atraso. Foram observadas obras de concreto armado (convencional), alvenaria estrutural e paredes de concreto moldadas no local. Para a análise dos dados foi criado um fator de atraso e aplicada uma metodologia de classificação das causas em níveis de risco através da análise de clusters. Como resultados foram apontadas as principais causas de variabilidade para cada um dos sistemas, sendo algumas semelhantes: retrabalho, baixa qualidade do trabalho e socialização. Análises estatísticas apontaram diferenças entre os sistemas: aqueles mais industrializados tiveram maior quantidade de causas classificadas em níveis de alto risco, porém o impacto da variabilidade no processo foi menor. Há deficiências por parte dos gestores para lidar com os impactos da variabilidade nos processos.

Palavras-chave: Causas da variabilidade. Processos. Sistemas construtivos.

Herbert Melo Cruz Universidade Federal de Sergipe São Cristóvão - SE - Brasil

Débora de Gois Santos Universidade Federal de Sergipe São Cristóvão - SE - Brasil

Ludmilson Abritta Mendes Universidade Federal de Sergipe São Cristóvão - SE - Brasil

Recebido em 10/05/17 Aceito em 20/09/17

\begin{abstract}
One of the major challenges faced by construction management is the implementation of activities within schedule, as variability often occurs. This research study aims to analyse the causes of variability in the execution time of processes in different construction systems, classifying them into different risk levels. The methodology consisted of a field study, where a questionnaire with 31 causes of variability divided into categories was applied to several construction workers. Our aim was to detect the frequency and intensity of delays. The study analysed reinforced concrete works (conventional), structural masonry and concrete walls cast on-site. For the data analysis, a delay factor was created and we classified the causes into risk levels by using cluster analysis. The results showed the main causes of variability for each one of the systems, and pointed to similarities: rework, low quality of work, socialisation. Statistical analyses showed differences between systems: the more industrialised systems had a greater number of causes classified at high-risk levels, but the impact of variability in the process was smaller. The study also showed deficiencies, on the part of managers, to deal with the impacts of process variability.

Keywords: Causes of variability. Processes. Construction system.
\end{abstract}




\section{Introdução}

Um dos problemas gerenciais que ainda desafiam as empresas construtoras é o cumprimento da programação das atividades, ou seja, executá-las em tempo consoante ao planejado. Os atrasos no ambiente da construção são comuns, o que afeta algumas atividades ou todo o fluxo de produção em virtude do andamento sequencial deste (TOMMELEIN; RILEY; HOWELL, 1999).

Esses desvios são reconhecidos por alguns autores (TOMMELEIN; RILEY; HOWELL, 1999; WAMBEKE; HSIANG; LIU, 2011; RUSSELL et al., 2013) como um tipo específico de variabilidade relacionado ao tempo de execução dos processos. Essas pesquisas focaram no estudo do impacto da variabilidade na produtividade do trabalho e na programação das obras.

Outros autores (MYDIN et al., 2014; DE FILIPPI; MELHADO, 2015; REIS et al., 2016) tratam em suas pesquisas sobre os atrasos de obras, ou seja, o desvio relacionado ao tempo de execução do empreendimento como um todo. De Filippi e Melhado (2015) definem que essas causas de atrasos estão relacionadas a empreendimentos que tiveram impactados seus prazos contratuais.

Apesar de perspectivas diferentes, essas duas linhas de pesquisas se complementam, inclusive quanto às causas que levam às ocorrências desses desvios.

De Filippi e Melhado (2015) salientam que as empresas não atrasam suas obras em busca de benefícios, mas por não conseguirem cumprir o planejamento. Então, quais as causas que levam a essa situação de variabilidade? Para essa análise, autores têm empregado diferentes metodologias a fim de obter a classificação e medir o impacto das causas de variabilidade ou fatores que levam ao atraso das obras.

Algumas metodologias estão baseadas na teoria de gerenciamento de riscos, que é uma componentechave do gerenciamento de projetos. Para Pawar, Bajad e Shinde (2017), os riscos não gerenciados ou altos são uma das principais causas de falhas em projetos. Essas metodologias têm em comum o princípio de indicar os riscos - de causas de variabilidade ou atraso - a partir das componentes frequência de ocorrência e impacto no tempo de execução. Alguns exemplos são fator de atraso e classificação de causas em níveis de risco (RUSSELL et al., 2013), e índice de importância (PATEL; RATHOD; SHARMA, 2016; PAWAR; BAJAD; SHINDE, 2017).

Já outros autores utilizam metodologias que levam em consideração somente uma componente, tal como horas de atraso (WAMBEKE; HSIANG;
LIU, 2011), porcentagem de respostas afirmativas de ocorrência (DE FILIPPI; MELHADO, 2015; REIS et al., 2016) e grau de importância do atraso (SHA et al., 2017).

As pesquisas levantadas na literatura sobre o assunto apresentam algumas similaridades conceituais e metodológicas, considerando a influência de algumas peculiaridades nos resultados (como local da pesquisa e função hierárquica dos entrevistados). Wambeke, Hsiang e Liu (2011) discutem as diferentes visões dos engenheiros, empreiteiros e operários americanos na classificação das causas da variabilidade; De Filippi e Melhado (2015) levantaram as causas de atrasos em obras em São Paulo e concluíram que os resultados são influenciados pelas características e cultura local; Sha et al. (2017) comparam as classificações de consultores e empreiteiros quanto aos atrasos em projetos de construção no Nepal.

Foi constatado que os campos de observação dessas pesquisas tratam de empreendimentos de construção sem discutir a influência dos sistemas construtivos empregados nas obras. Apesar disso, as peculiaridades executivas dos diferentes sistemas construtivos interferem na organização de seus ciclos, consequentemente podendo ter influência na presença da variabilidade no processo de construção. Essa discussão é aprofundada no referencial teórico.

Visando preencher as lacunas do campo conceitual sobre o assunto quanto às influências dos sistemas construtivos e os poucos trabalhos nacionais que versam sobre o tema, este estudo disponibiliza um método e base de dados que possam ser utilizados e comparados em pesquisas futuras. $\mathrm{O}$ objetivo deste trabalho foi analisar as causas que afetam a variabilidade do tempo de execução dos processos em diferentes sistemas construtivos e classificá-las em níveis de risco.

\section{Referencial teórico}

O referencial teórico é iniciado discutindo-se as características executivas dos sistemas construtivos foco da pesquisa. A seguir, o tema da variabilidade na construção é conceituado a partir dos resultados de um mapeamento sistemático da literatura, sendo por fim discutidas as principais causas da variabilidade na construção que foram elencadas da literatura.

\section{Sistemas construtivos}

Entre os sistemas construtivos mais usuais e que são foco de análise desta pesquisa podem-se citar: o de 
estrutura de concreto armado com vedação em alvenaria; a alvenaria estrutural; e o sistema de paredes de concreto moldadas no local. Eles abrangem um conjunto de métodos construtivos comumente empregados que se interagem de maneira peculiar em cada um desses sistemas.

Uma das principais diferenças entre esses sistemas construtivos são suas etapas de execução, o que impacta diretamente na organização e na redução da quantidade de ciclos. A Figura 1 mostra a organização dos ciclos referentes às etapas executivas de estrutura e vedação, e, além disso, às respectivas atividades de fluxo que existem entre eles.

As atividades de fluxo são representadas pelos quadros brancos, e os ciclos são representados pelos quadros cinza, que trazem a descrição dos respectivos pacotes de trabalho.

Conforme a Figura 1, para que se chegue a um estágio que estejam executadas a estrutura, a vedação, parte de algumas instalações (hidráulica e elétrica) e o revestimento das paredes (reboco), são necessários cinco ciclos para o sistema de concreto armado com vedação em alvenaria (CAVA); dois ciclos para o sistema de alvenaria estrutural (AE); e somente um ciclo para o sistema de paredes de concreto moldadas no local (PCML).

Logo, a partir da diminuição desses ciclos, ocorre também a redução das atividades de fluxo - quadros brancos - e, por consequência, a possibilidade de que ocorram menos variabilidades (atrasos na conclusão dos pacotes de trabalho, retrabalhos, falhas no produto que comprometam o próximo serviço, entre outros) (FORMOSO, 2002).
De forma peculiar, na construção os produtos que estão sendo construídos tendem a ser estacionários, enquanto as equipes especializadas movimentam-se de um local para outro, concluindo um trabalho que é pré-requisito para a entrada da próxima equipe. Assim como nas demais indústrias, tem-se então um sistema de produção com estações de processamento em que há a transferência do trabalho parcialmente concluído - handoffs - entre as equipes (TOMMELEIN; RILEY; HOWELL, 1999).

As características organizacionais dos sistemas construtivos quanto a seus ciclos influenciam na ocorrência de handoffs. Ciclos em menores quantidades que englobam mais atividades diminuem a transferência de trabalho entre equipes e o deslocamento delas no fluxo de produção. Isso pode evitar a variabilidade, seja esta geométrica ou relativa ao tempo de execução.

\section{Variabilidade na construção}

Um mapeamento sistemático da literatura (MSL) foi realizado com o objetivo de descrever os estudos sobre o tema deste trabalho. Foram consultadas as bases de dados do Infohab e Google Acadêmico, além do Portal de Periódicos da Capes, que engloba a pesquisa nas bases da RCAAP, Scielo e Univates, voltadas à subárea Engenharia Civil. O Quadro 1 traz as pesquisas nacionais e internacionais dos últimos vinte anos, em ordem cronológica, focadas na variabilidade do tempo de execução ou atrasos em obras.

\section{Figura 1 - Organização dos ciclos em diferentes sistemas construtivos}

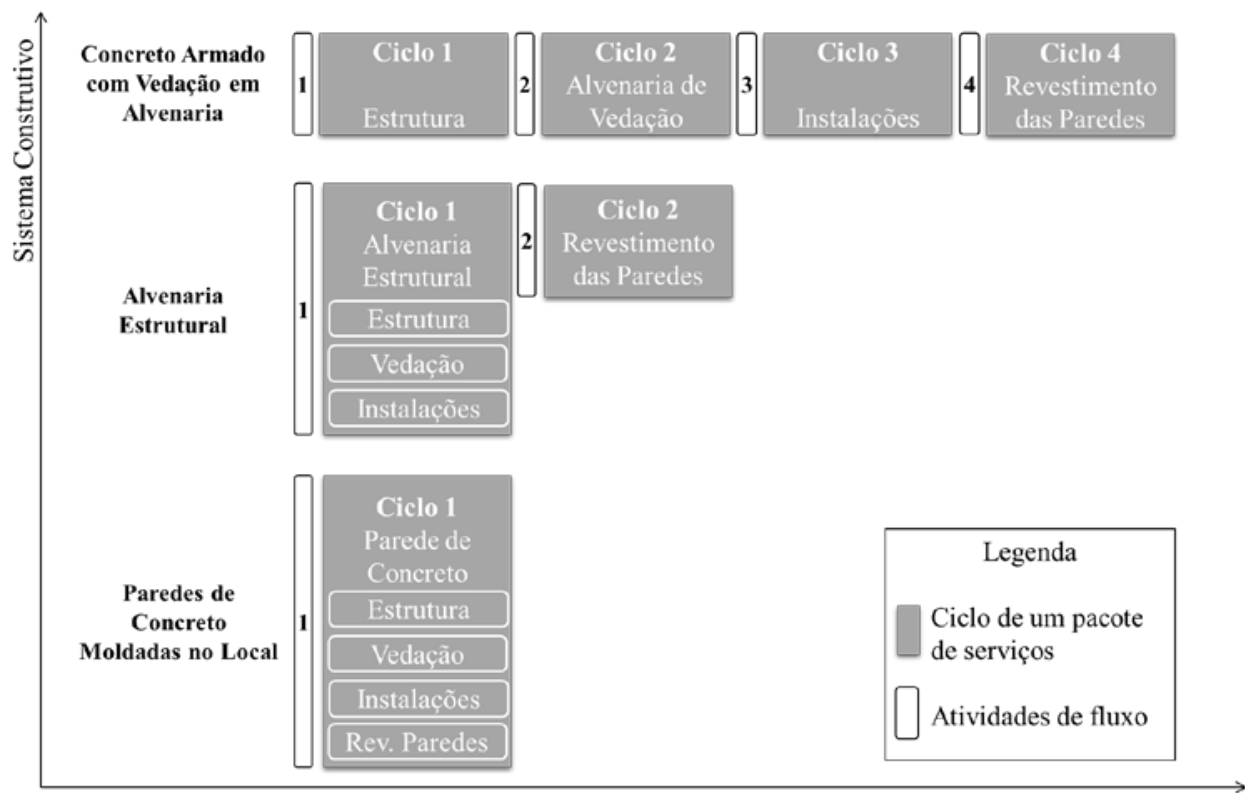


Quadro 1 - Mapeamento sistemático da literatura sobre variabilidade e atrasos

\begin{tabular}{|l|c|c|c|}
\hline \multicolumn{1}{|c|}{ Autores } & Ano & País & Termo pesquisado \\
\hline Tommelein, Riley e Howell & 1999 & EUA & Variability \\
\hline Santos, Formoso e Tookey & 2002 & Brasil/Inglaterra & Variabilidade \\
\hline De Mori e Jungles & 2005 & Brasil & Variabilidade \\
\hline Couto & 2006 & Portugal & Atrasos \\
\hline Sambasivan e Soon & 2007 & Malásia & Delay \\
\hline Oladapo & 2007 & África do Sul & Variation \\
\hline Vasconcelos & 2010 & Portugal & Atrasos \\
\hline Mohammad et al. & 2010 & Malásia & Variation \\
\hline Mota, Viana e Isatto & 2010 & Brasil & Variabilidade \\
\hline Pourrostam e Ismail & 2011 & Malásia & Delay \\
\hline Wambeke, Hsiang e Liu & 2011 & EUA & Variation \\
\hline Russell et al. & 2013 & EUA & Variation \\
\hline González et al. & 2014 & Espanha & Delay \\
\hline De Filippi e Melhado & 2015 & Brasil & Variabilidade \\
\hline Reis et al. & 2016 & Brasil & Atrasos \\
\hline Fazinga, Saffaro e Santana & 2016 & Brasil & Variabilidade \\
\hline Santos e Santos & 2017 & Brasil & Variabilidade \\
\hline Maués et al. & 2017 & Brasil & Delay \\
\hline Sha et al. & 2017 & Nepal & Delay \\
\hline
\end{tabular}

Segundo Maués et al. (2017), vários autores tratam sobre empresas que não conseguem cumprir os prazos na construção. A partir do MSL observa-se que esse problema tem mais interesse para países em desenvolvimento como Brasil, África do Sul e Malásia. Porém, é um assunto que não deixa de ser discutido em outros países, mostrando ser ainda um problema recorrente no ambiente da construção.

A variabilidade na construção pode ser classificada em três categorias:

variabilidade de tempo do processamento; variabilidade de fluxo; e variabilidade geométrica. As duas primeiras estão ligadas às variações de tempo observadas na execução dos processos, tendo como parâmetro comparativo a programação de atividades. $\mathrm{O}$ foco deste trabalho é justamente nas causas dessas variabilidades relacionadas ao tempo de execução. A variabilidade geométrica tem ligação com a qualidade da produção, e sua definição é importante porque tem relação com a ocorrência das outras duas categorias. Adiante são conceituadas as especificidades das categorias de variabilidade.

A variabilidade de tempo de processamento, segundo Koskela (2000), refere-se ao tempo necessário para processar uma tarefa em uma estação de trabalho. Hopp e Spearman (1996) ligam esse tipo de variabilidade aos efeitos que estão confinados à estação de trabalho. Alguns autores (KOSKELA, 2000; SANTOS; FORMOSO; TOOKEY, 2002) a exemplificam como sendo as ocorrências de quebra de máquinas, falhas aleatórias e retrabalhos por qualidade inaceitável, entre outras.

A variabilidade de fluxo é definida por Santos, Formoso e Tookey (2002) como aquela que ocorre quando a variabilidade em uma estação de trabalho afeta o comportamento de outras estações de trabalho, que estão a montante ou a jusante. É um tipo de variabilidade observado nos fluxos entre as estações de trabalho devido ao sequenciamento das atividades na construção. Para os autores supracitados, o tempo de processamento representa uma pequena fração do fluxo de produção real; sendo assim, mais tempo é gasto esperando por vários recursos (pessoal, material, máquinas).

Outro tipo de variabilidade, conceituado por Koskela (2000), é denominado de variabilidade dimensional, que é ligada à variação geométrica de um produto na saída de uma tarefa. Essa variabilidade dimensional pode ocasionar a variabilidade do tempo de processamento, já que leva a retrabalhos com rejeição e correção de produtos.

Para Wambeke, Hsiang e Liu (2011), a variabilidade quase sempre existe no processo de construção e, consequentemente, tem impacto significativo na produtividade do trabalho. O impacto da variabilidade pode ser maior por conta da natureza sequencial das atividades na construção, que resulta em um efeito acumulativo 
em relação à variabilidade no fluxo de produção (HAJIFATHALIAN, 2011).

Um mapa conceitual traz as relações entre as categorias de variabilidade presentes no processo da construção (Figura 2). Observa-se que ter as condições prévias para a execução das atividades é elemento fundamental para prevenir a variabilidade. Outra análise importante é que a ocorrência dos diversos tipos de variabilidade (no fluxo de produção ou geométrica) pode levar a desvios entre a programação e o tempo de execução das atividades.

Por exemplo, quando ocorre variabilidade geométrica, tal como a execução de um produto defeituoso (uma parede desaprumada), em algum momento isso terá que ser corrigido. Haverá, então, aumento na duração do tempo de execução da tarefa sucessora (reboco) devido às correções da baixa qualidade do trabalho anterior. Essa variabilidade no tempo de processamento pode ainda afetar as tarefas posteriores por conta da natureza sequencial do fluxo de produção e, consequentemente, da programação. Isso evidencia a interligação entre os diferentes tipos de variabilidade e o impacto final nos desvios de tempo da programação.

A presença da perda por making-do é evidenciada na Figura 2. Koskela (2004) propõe a perda por making-do quando uma tarefa é iniciada sem que as condições prévias para sua realização estejam disponíveis, o que acarreta na diminuição do ritmo produtivo. As condições prévias são discutidas mais detalhadamente em Causas da variabilidade.
Entre as consequências técnicas do making-do, destaca-se o aumento do tempo de processamento e sua variabilidade; além disso, pode haver a queda da qualidade do produto, ocorrendo a variabilidade geométrica (KOSKELA, 2004).

\section{Causas da variabilidade}

A partir da revisão da literatura, identificou-se um número considerável de pesquisas que definem a variabilidade e suas influências no processo da construção, porém há uma lacuna sobre a identificação das reais causas dessa variabilidade. Wambeke, Hsiang e Liu (2011) confirmaram essa peculiaridade em seu trabalho após realizarem uma vasta pesquisa bibliográfica sobre o assunto. Por outro lado, esses autores salientam que há uma quantidade significativa de pesquisas sobre fatores que afetam a produtividade na construção que estão relacionados com as causas da variabilidade.

Muitos fatores que podem ser considerados como causas da variabilidade são encontrados na literatura ou facilmente visualizados no cotidiano da construção, entre eles falhas na entrega de materiais, quebra de equipamentos e ferramentas, falta de informações, falta de recursos, desmotivação da mão de obra, problemas externos (chuva, calor) e outros. Esses fatores podem estar relacionados entre si e agrupados em categorias, se for considerada a conceituação de Koskela (2000) sobre as condições prévias para a execução das tarefas na construção.

Figura 2 - Mapa conceitual das relações da variabilidade no processo de construção

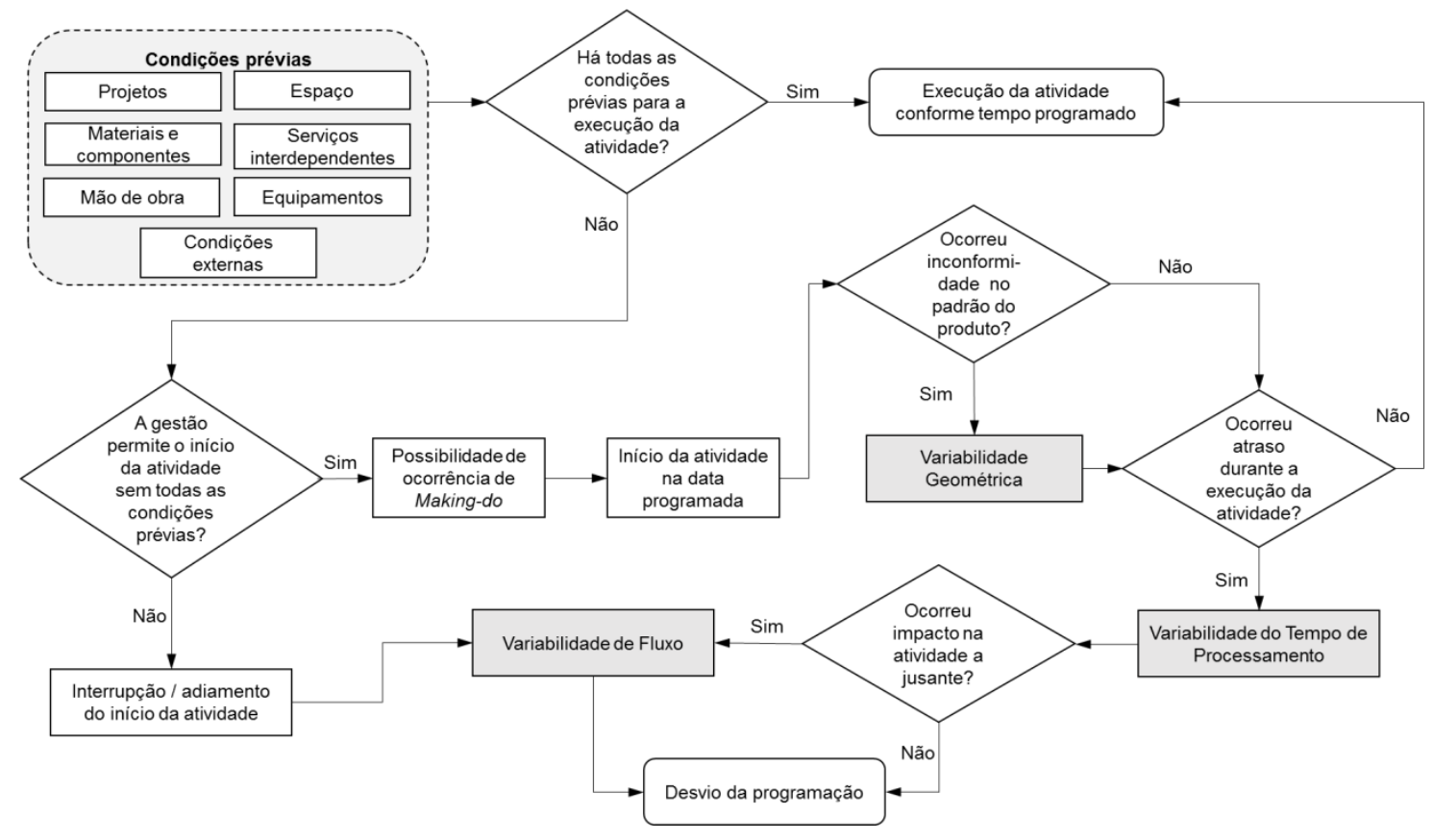


Koskela (2000) define sete condições que se unem para gerar a sequência de tarefas na construção:

(a) projetos;

(b) materiais e componentes;

(c) mão de obra;

(d) equipamentos;

(e) espaço;

(f) serviços interdependentes; e

(g) condições externas.

Segundo o autor, muitos desses fluxos de recursos (condições) são de alta variabilidade devido às peculiaridades da construção, o que aumenta a probabilidade de uma entrada estar em falta. Essa situação pode ser observada na Figura 2, acima.

O autor supracitado (KOSKELA, 2000) exemplifica:

(a) os projetos detalhados podem faltar no início de um trabalho;

(b) os erros em projetos ou peças pré-fabricadas podem surgir durante a execução no local;

(c) as condições externas (chuva, vento, temperaturas extremas) podem atrasar o andamento do trabalho;

(d) a produtividade do trabalho manual é variável;

(e) pode faltar espaço; e

(f) há trabalhos interligados que dependem do andamento de tarefas anteriores.

Se essas sete condições forem analisadas mais a fundo, podem-se encontrar diversos fatores que causam a variabilidade na construção.

Wambeke, Hsiang e Liu (2011) identificaram na bibliografia sobre o assunto e em entrevistas com profissionais do setor 50 causas de variabilidade, dividindo-as em oito categorias: as sete condições prévias de Koskela (2000) e uma denominada gestão, supervisão e fluxo de informações. A pesquisa identificou as principais causas de variabilidade na duração das tarefas, sendo algumas delas dúvidas de projetos, terminalidade do trabalho prévio, obtenção de autorizações e qualidade dos documentos.

De Filippi e Melhado (2015) identificaram na literatura 100 causas de atrasos de empreendimentos ligadas a fatores externos (chuvas, solo, mercado, cliente) e internos. Os resultados da pesquisa mostraram que os atrasos ocorrem mais por questões internas (organização do canteiro e gestão).

Reis et al. (2016) levantaram 56 fatores de atrasos de obra. Como resultados a pesquisa mostrou que os principais atrasos classificados pelos entrevistados são relacionados à gestão da obra, tais como retrabalho, baixa produtividade da mão de obra e condições meteorológicas. Segundo os autores, esses fatores foram comuns aos de outras pesquisas sobre 0 assunto.

Muitas das causas identificadas por De Filippi e Melhado (2015) e Reis et al. (2016), apesar de estarem relacionadas com os atrasos de empreendimentos, podem ser relacionadas às causas da variabilidade foco desta pesquisa, inclusive algumas são semelhantes às apontadas por Wambeke, Hsiang e Liu (2011).

Para Wambeke, Hsiang e Liu (2011), priorizar as causas de variabilidade a serem combatidas é importante para os gestores, pois permite obter maior economia no processo construtivo. Em outras palavras, eles podem concentrar seus esforços na eliminação das causas da variabilidade que fornecerão o maior benefício em termos de desempenho do projeto.

\section{Método}

A estratégia de pesquisa adotada foi o estudo de casos múltiplos de caráter exploratório e pesquisa qualiquantitativa, por ser a mais adequada aos objetivos do trabalho de comparar diferentes sistemas construtivos. Para Yin (2001), quando o mesmo estudo contém mais de um caso único, é preciso utilizar um projeto de casos múltiplos. Para a coleta de dados a principal ferramenta utilizada foi o questionário de causas da variabilidade, além de entrevistas semiestruturadas com engenheiros e mestres, e observações diretas.

Existiam durante o período de coleta de dados 43 obras em execução na Grande Aracaju, SE, que foram submetidas a um processo de seleção considerando os requisitos tipo de sistema construtivo - concreto armado com vedação em alvenaria (CAVA), alvenaria estrutural (AE) e paredes de concreto moldadas no local (PCML); fase de execução intermediária; e construtora de médio/grande porte. Restaram então nove obras como objeto de estudo, três de cada um dos sistemas construtivos.

Ressalta-se que a amostra de obras da pesquisa tem representatividade local, não sendo permitidas extrapolações e generalizações sobre os resultados com elevado grau de segurança, conforme Maia e Iarozinski Neto (2016). De Filippi e Melhado (2015) frisam a importância de relacionar os dados obtidos em pesquisas de atrasos de obras com as características do mercado de construção onde elas foram realizadas. 


\section{Descrição do questionário e coleta de dados}

O questionário de causas da variabilidade (Quadro 2) para aplicação com engenheiros, mestres e operários contém 31 causas agrupadas em oito categorias, sete destas baseadas nas condições prévias de Koskela (2000) - pré-requisito do trabalho, detalhamento do projeto e método do trabalho, mão de obra, ferramentas e equipamentos, materiais e componentes, condições de trabalho e do local de trabalho, e condições climáticas - e uma relativa à gestão e fluxo de informações. Essa divisão foi utilizada com sucesso por Wambeke, Hsiang e Liu (2011) e por Russell et al. (2013) em pesquisas sobre causas de variabilidade e buffer de tempo.

Para Martins e Theóphilo (2009), os questionários podem avaliar diversas variáveis, sendo elas de dois tipos principais: quantitativas e qualitativas. Conforme os autores supracitados, as variáveis qualitativas podem ser adaptadas para representar uma série quantitativa utilizando escalas construídas através de sequências de enunciados, atribuindo-as pesos. Esse procedimento permite que os dados sejam tratados com o emprego de ferramentas estatísticas visando à obtenção de informações acerca da amostra (MAIA; IAROZINSKI NETO, 2016).

\section{Quadro 2 - Questionário de causas da variabilidade}

\begin{tabular}{|c|c|c|}
\hline Grupo & & Causa \\
\hline \multirow{5}{*}{$\begin{array}{l}\text { 1. Pré- } \\
\text { requisitos do } \\
\text { trabalho }\end{array}$} & 1 & Obtenção de autorizações para iniciar o trabalho \\
\hline & 2 & Conclusão dos trabalhos prévios (trabalho anterior que ainda não foi realizado) \\
\hline & 3 & Retrabalho exigido devido à qualidade do trabalho anterior \\
\hline & 4 & Baixa qualidade do trabalho anterior (nível que ainda não requer retrabalho) \\
\hline & 5 & Inspeções de trabalhos previamente concluídos \\
\hline \multirow{6}{*}{$\begin{array}{l}2 . \\
\text { Detalhamento } \\
\text { do projeto e } \\
\text { método de } \\
\text { trabalho }\end{array}$} & 6 & Construtibilidade do projeto \\
\hline & 7 & Qualidade dos documentos (erros no projeto e/ou desenhos) \\
\hline & 8 & Requisitos de controle de qualidade \\
\hline & 9 & Complexidade do trabalho \\
\hline & 10 & Planejamento da sequência ou método do trabalho \\
\hline & 11 & $\begin{array}{l}\text { Baixo grau de repetição (incapacidade de desenvolver um sistema eficiente devido a } \\
\text { atividades em constante mudança) }\end{array}$ \\
\hline \multirow{5}{*}{ 3. Mão de obra } & 12 & Socialização (conversas com colegas de trabalho) \\
\hline & 13 & Absentismo (faltas) \\
\hline & 14 & $\begin{array}{l}\text { Pessoas que chegam tarde e/ou saem mais cedo por causa de doença, acidente ou } \\
\text { motivo pessoal }\end{array}$ \\
\hline & 15 & Baixa disposição e/ou falta de motivação \\
\hline & 16 & $\begin{array}{l}\text { Falta de habilidade dos trabalhadores/equipes na execução de tarefas que foram } \\
\text { pedidas a eles }\end{array}$ \\
\hline \multirow{3}{*}{$\begin{array}{l}\text { 4. Ferramentas } \\
\text { e } \\
\text { equipamentos }\end{array}$} & 17 & Confiabilidade de equipamentos ou ferramentas \\
\hline & 18 & Disponibilidade de equipamento ou ferramentas \\
\hline & 19 & Capacidade (produtividade) de equipamentos e ferramentas \\
\hline \multirow{3}{*}{$\begin{array}{l}\text { 5. Materiais e } \\
\text { componentes }\end{array}$} & 20 & Falhas no recebimento dos materiais (quantidade ou tipo incorreto) \\
\hline & 21 & Tentativa de solicitação de materiais para serem utilizados \\
\hline & 22 & $\begin{array}{l}\text { Recebimento de materiais para a atividade mais tarde do que o programado / } \\
\text { esperado }\end{array}$ \\
\hline \multirow{3}{*}{$\begin{array}{l}\text { 6. Condições } \\
\text { de trabalho e } \\
\text { do local de } \\
\text { trabalho }\end{array}$} & 23 & Área de trabalho superlotada ou desordenada/canteiro de obras congestionado \\
\hline & 24 & $\begin{array}{l}\text { Layout do local de trabalho: distância excessiva entre o local de armazenamento do } \\
\text { material e o local de sua utilização }\end{array}$ \\
\hline & 25 & Forma de transporte do material do local de armazenamento até o local de utilização \\
\hline \multirow{5}{*}{$\begin{array}{l}\text { 7. Gestão, } \\
\text { supervisão e } \\
\text { fluxo de } \\
\text { informações }\end{array}$} & 26 & Espera para obter respostas sobre perguntas ou orientações sobre o projeto \\
\hline & 27 & Pouco compromisso por causa de um cronograma de trabalho apertado \\
\hline & 28 & Mudanças nas atividades causadas por alterações (do cliente, dono da obra) \\
\hline & 29 & Comunicação entre engenheiro da obra e mestre/encarregado \\
\hline & 30 & Comunicação entre mestre/encarregado e operários \\
\hline $\begin{array}{l}\text { 8. Condições } \\
\text { climáticas }\end{array}$ & 31 & Impactos climáticos (calor excessivo, frio, vento, chuva) \\
\hline
\end{tabular}


Duas variáveis de análise são apresentadas no questionário da pesquisa: a intensidade, cuja causa impacta no processo (horas de atraso); e a frequência, cuja causa ocorre no processo. Ambas tinham um horizonte de análise de 1 semana de trabalho. A característica quantitativa das variáveis foi mensurada a partir de escalas semânticas em que o respondente escolhe o grau que representa sua opinião, conforme descrito no Quadro 3.

A escolha pelo uso de escalas foi baseada em três motivos: são instrumentos simples e objetivos para medir opiniões (GIL, 1999), sendo adequados aos diferentes níveis culturais dos respondentes; são ferramentas que estão alinhadas com as necessidades do procedimento de análise em níveis de riscos, descrito em Procedimentos de análise; e foram utilizadas com sucesso em pesquisas anteriores com objetivos semelhantes - Russell et al. (2013), Patel, Rathod e Sharma (2016) e Pawar, Bajad e Shinde (2017).

Maia e Iarozinski Neto (2016) salientam que os resultados finais obtidos a partir do emprego de escalas devem ser analisados como tendências, e não como valores absolutos. Essa consideração é baseada em Samartini (2006), que descreve o caráter subjetivo acrescentado às análises pelo uso das escalas.

Após sua elaboração, o questionário foi submetido a uma avaliação por especialistas, seguido de um processo de validação, através de uma aplicação piloto em uma obra, visando avaliar sua clareza, tempo de resposta e nível de complexidade. A partir das sugestões dos participantes foram retirados e reescritos alguns itens. A complexidade foi avaliada como adequada aos três níveis hierárquicos.

Decidiu-se que a aplicação se daria de forma presencial, sobretudo por conta da participação dos operários e mestres, que em certos casos necessitariam de mais explicações sobre a abordagem do questionário. Esse tipo de aplicação objetivou possibilitar um melhor esclarecimento das ideias aos respondentes, diminuindo a subjetividade e erros por falta de entendimento.

As visitas foram iniciadas a partir da entrevista com o engenheiro da obra, visando identificar as peculiaridades e os aspectos da gestão, além de discutir sobre o tema da variabilidade. Após os procedimentos iniciais, era solicitado aos engenheiros e mestres que respondessem ao questionário.

Em seguida, o entrevistador direcionava-se aos operários em campo de forma aleatória solicitando a participação na pesquisa. A amostra dos operários, devido ao tamanho da população e sua diversidade de subgrupos, foi do tipo estratificada e de tamanho restrito. Gil (1999) define que uma amostra estratificada é caracterizada pela seleção de uma amostra de cada grupo da população considerada (ex.: serviço de alvenaria, estrutura, revestimento, etc.). Segundo o referido autor, deve-se selecionar do universo uma amostra aleatória proporcional à extensão de cada grupo.

A Tabela 1 detalha o perfil da amostra de respondentes do questionário.

Quadro 3 - Escala das variáveis

\begin{tabular}{|c|c|c|c|c|c|c|}
\hline Grau & 0 & 1 & 2 & 3 & 4 & 5 \\
\hline Intensidade & $\begin{array}{c}\text { Não } \\
\text { ocorre }\end{array}$ & $\begin{array}{c}\text { Muito } \\
\text { baixa }\end{array}$ & Baixa & Média & Muito alta & Alta \\
\hline Frequência & $\begin{array}{c}\text { Não } \\
\text { ocorre }\end{array}$ & Rara & $\begin{array}{c}\text { Pouco } \\
\text { provável }\end{array}$ & Possível & Provável & Sempre \\
\hline
\end{tabular}

Tabela 1 - Perfil da amostra de respondentes

\begin{tabular}{c|c|c|c}
\hline Sistema & Engenheiros & Mestres & Operários \\
\hline CAVA & 3 & 3 & 29 \\
\hline AE & 3 & 3 & 27 \\
\hline PCML & 5 & 3 & 44 \\
\hline Total & $\mathbf{1 1}$ & $\mathbf{9}$ & $\mathbf{1 0 0}$ \\
\hline
\end{tabular}




\section{Procedimentos de análise}

Os dados dos questionários foram inseridos em planilhas eletrônicas, sendo agrupados por sistemas construtivos. Após testes utilizando a média e a mediana, optou-se por utilizar a média como medida de tendência central dos dados, por esta mostrar-se mais adequada para executar a análise de níveis de risco, além de não apresentar diferenças significativas nos demais resultados da pesquisa. Uma limitação da média é sua sensibilidade a valores extremos da amostra, denominados de outliers (MORETTIN; BUSSAB, 2012). Para lidar com esse problema, um procedimento comum é eliminar respostas que apresentem esses outliers.

Para evitar distorções nos cálculos das médias, já que os tamanhos das amostras dos três níveis hierárquicos foram consideravelmente diferentes, calculou-se primeiro a média das respostas para cada um deles, sendo a média final do sistema construtivo calculada a partir das três médias anteriores.

O coeficiente de correlação linear foi calculado para analisar a relação entre as variáveis. Morettin e Bussab (2012) definem esse coeficiente como uma medida $(-1 \leq \operatorname{corr}(x, y) \leq 1)$ do grau de associação entre duas variáveis e também da proximidade dos dados a uma reta. A aproximação de zero indica a falta de associação, logo, quanto mais distante desse valor, maior a correlação entre as variáveis, sendo que para coeficientes positivos a distribuição dos dados se aproxima de uma reta crescente, e para coeficientes negativos, de uma reta decrescente.

Os gráficos foram elaborados a partir das variáveis intensidade (I) e frequência (F), que representavam os valores da média geral de cada sistema. Foram plotados os valores de I (eixo Y) e F (eixo X) das 31 causas.

Já que o questionário aplicado levantou duas variáveis para interpretar cada uma das causas, foi criado um coeficiente denominado fator de atraso (FA) (Russell et al., 2013), como sendo o produto da intensidade (I) e da frequência $(\mathrm{F}): F A=I \times F$. O fator de atraso auxiliou na formação do ranking das causas, que traz as oito (25\%) mais relevantes. Para cada sistema construtivo também foi feita a soma do fator de atraso (SFA) das causas do ranking.

A comparação estatística entre os dados dos sistemas construtivos foi realizada através do teste $\mathrm{t}$ de Student, com nível de confiança adotado de 95\%. Utilizou-se o programa MS Excel ${ }^{\circledR}$ para calcular os valores t crit (t crítico), t calc (t calculado) e p-valor, possibilitando os testes das hipóteses de forma bicaudal.

Outro objetivo da pesquisa foi classificar as causas da variabilidade em níveis de risco.
Segundo Russell (2013), toda atividade, seja ela da construção ou com outra finalidade, envolve algum risco (econômico, social, acidental, político, de saúde). Para o autor, embora esses riscos não possam ser totalmente evitados, podem ser avaliados e minimizados.

$\mathrm{O}$ risco tem duas componentes: uma probabilidade de ocorrência e uma consequência dessa ocorrência. A probabilidade é definida como a frequência em que o evento ocorrerá, e a consequência pode ser definida como um impacto, seja ele no custo, na programação ou em um parâmetro de desempenho (WHEELER, 2002; RUSSELL et al., 2013).

Nesta pesquisa as causas foram agrupadas em níveis de riscos considerando as variáveis intensidade e frequência, conforme mencionado anteriormente. Após a elaboração dos gráficos (I x F), foi feita uma análise para dividir seus pontos em quatro níveis de risco utilizando-se a ferramenta de análise de clusters com o auxílio do programa estatístico IBM SPSS Statistics ${ }^{\odot}$. Russell et al. (2013) utilizaram uma metodologia semelhante para agrupar os fatores causadores de buffers de tempo em níveis de risco.

A análise de clusters é uma técnica de análise multivariada que possibilita agrupar variáveis em grupos com características comuns a partir das distâncias entre seus membros (MAROCO, 2007). O processo se iniciou com a alimentação dos dados referentes às 31 causas no programa. Utilizou-se o agrupamento hierárquico de clusters para a formação dos grupos a partir dos métodos menor distância, maior distância e Ward. Segundo Maroco (2007), esses métodos diferem-se pela forma em que o algoritmo agrupa ou desagrupa os elementos; sua escolha se dá pelas vantagens comparativas de sua aplicação, que passa a ser mais adequada a depender de como se apresentam os elementos. O programa estatístico disponibilizou como saída um dendograma, que ilustra os agrupamentos efetuados e a distância entre os membros do cluster, sendo possível identificar quais membros pertenciam aos quatro grupos (representando os níveis de riscos). Esses resultados também foram apresentados em forma de tabelas. Após essa definição foram desenhadas em cada gráfico as quatro caixas para representar esses níveis. Mais detalhes sobre o processo de análise de clusters podem ser encontrados em Maroco (2007).

\section{Resultados}

Os resultados trazem inicialmente a análise das causas da variabilidade do tempo de execução dos processos através da elaboração de rankings a partir dos valores do fator de atraso por ser um coeficiente que incorpora as duas variáveis levantadas 
(intensidade e frequência). Em seguida, é apresentada a análise dos potenciais riscos dessa variabilidade associados aos sistemas construtivos através de gráficos que trazem o agrupamento das causas em níveis de risco. Obtiveram-se resultados para cada um dos três sistemas construtivos, o que possibilitou a análise da hipótese inicial do trabalho de que eles influenciam na presença da variabilidade.

\section{Análise das causas de variabilidade a partir do fator de atraso}

A Tabela 2 traz o ranking das oito principais causas e foi elaborado a partir dos valores do fator de atraso para cada um dos sistemas construtivos analisados.

O teste t de Student foi aplicado para comparação dos dados de fator de atraso entre os três sistemas construtivos após verificar que as amostras seguem distribuição normal.
Para se rejeitar a hipótese de que as médias entre dois sistemas comparados sejam iguais, é preciso atender às condições $T$ calculado $>T$ crítico e $p$ valor $<0,05$, considerando o nível de confiança de $95 \%$.

A partir dos resultados do teste $t$ (Tabela 3), podese sugerir diferença entre as médias do sistema CAVA e PCML. Isso pode indicar que a variabilidade esteja impactando menos esse sistema do que o CAVA.

As outras duas comparações (CAVA x AE e AE x PCML) indicaram que não se pode rejeitar a hipótese de que as médias sejam iguais, sugerindo que os sistemas comparados apresentam similaridades em termos de impacto das causas de variabilidade nesses sistemas, conforme os dados de fator de atraso.

Tabela 2 - Ranking das oito principais causas da variabilidade por sistema construtivo

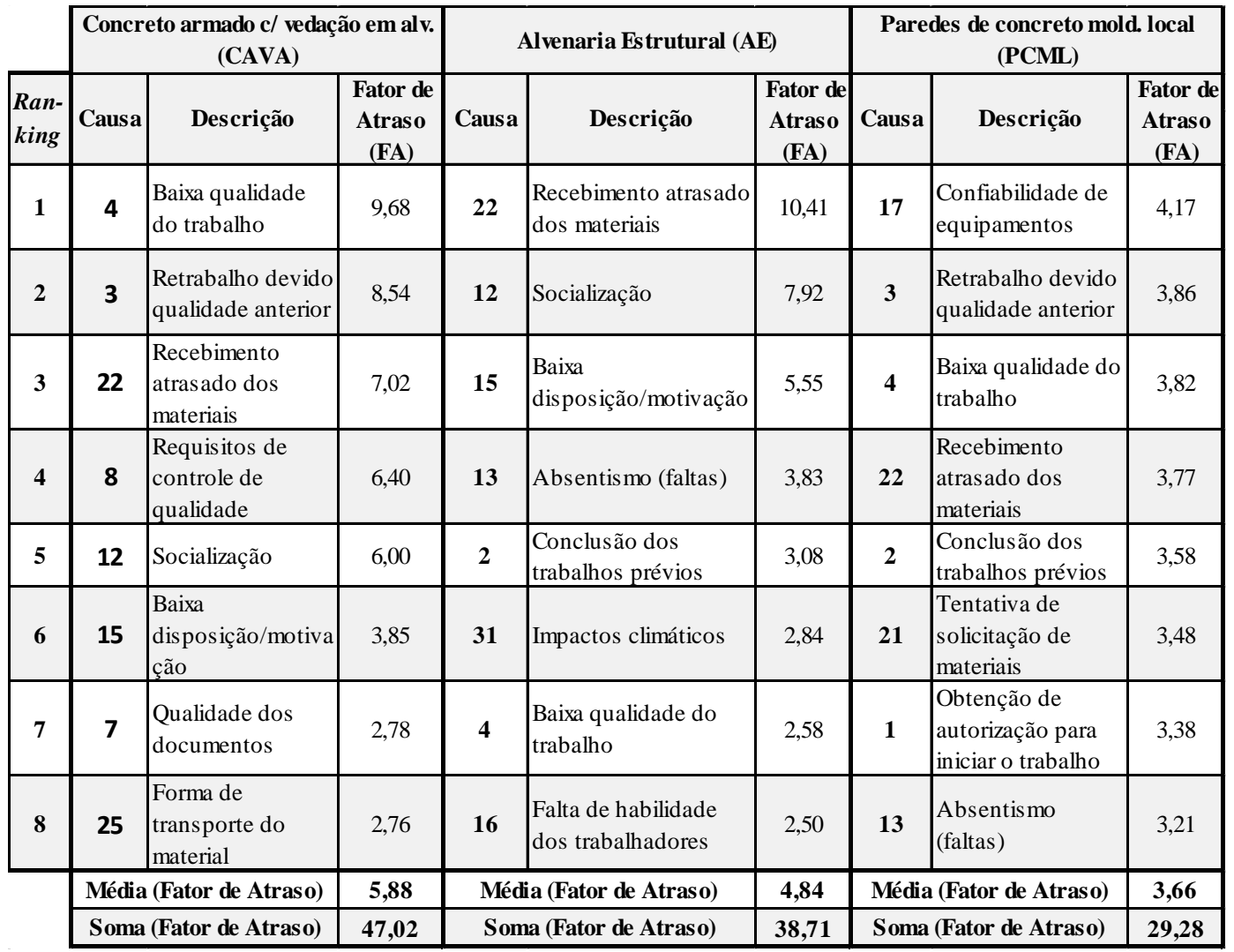


Tabela 3 - Resultados do teste t de Student

\begin{tabular}{c|c|c|c}
\hline \multirow{2}{*}{ Parâmetros } & \multicolumn{3}{|c}{ Comparação entre os sistemas } \\
\cline { 2 - 4 } & CAVA x AE & AE x PCML & CAVA x PCML \\
\hline t calculado & 0,75 & 1,13 & 2,41 \\
\hline t crítico & 2,14 & 2,36 & 2,36 \\
\hline p-valor & 0,46 & 0,29 & 0,05 \\
\hline $\begin{array}{c}\text { Diferença } \\
\text { entre médias }\end{array}$ & Não & Não & Sim \\
\hline
\end{tabular}

Observando a Tabela 2, as causas 22 (recebimento atrasado dos materiais) e 4 (qualidade do trabalho anterior) foram unânimes em todos os sistemas construtivos como algumas das principais causas de variabilidade, porém foram ordenadas de formas diferentes para cada um dos rankings. Já a causa 3 (retrabalho) aparece na segunda posição para o sistema CAVA e PCML.

Um dos fatores que podem ter influenciado o resultado da causa 22 no ranking do sistema $\mathrm{AE}$ foi a horizontalidade dos canteiros, típica dessas obras, que geralmente possuem muitas torres espalhadas em um terreno de grandes dimensões. Isso exige meios mais eficientes de movimentação de materiais na horizontal e na vertical. Caso não haja um planejamento e mecanismos eficientes, pode haver problemas na logística de entrega de materiais.

Essas três causas são comumente conhecidas no ambiente da construção, sendo identificadas em outros trabalhos. Reis et al. (2016) indicam como as principais causas de atrasos em obras o atraso na entrega de materiais e os retrabalhos devido a erros durante a construção. De Filippi e Melhado (2015) também encontraram em sua pesquisa o retrabalho devido a erros na construção e atraso na entrega de materiais como respectivamente a sétima e a nona causas mais frequentes de atrasos em obras.

Duas causas pertencentes à categoria mão de obra 12 (socialização) e 15 (baixa disposição) - foram classificadas nos rankings dos sistemas CAVA e AE. Isso pode indicar uma baixa disposição da mão de obra com o trabalho, acarretando na diminuição da produtividade. A situação é mais grave no sistema AE, que contém, além dessas duas causas, outras relacionadas a problemas com mão de obra: 13 (absentismo) e 16 (falta de habilidade dos trabalhadores). Resultados semelhantes foram discutidos em outras pesquisas do gênero.

Wambeke, Hsiang e Liu (2011) encontraram em sua pesquisa a socialização como o quarto fator de atraso de atividades. Reis et al. (2016) indicam como uma das principais causas de atraso em obras o baixo compromisso da mão de obra e o baixo nível de produtividade. De Filippi e Melhado (2015) indicam o baixo nível de produtividade da mão de obra como a quinta causa mais relevante de atraso em obras.

Ao analisar o ranking do sistema CAVA, observase que a causa 25 (forma de transporte dos materiais) destacou-se entre as principais, o que reflete uma situação comum nesse tipo de sistema construtivo. Apesar de a movimentação de materiais dessas obras ser predominantemente vertical, a ocorrência de atrasos e paradas por conta de falhas no sistema de transporte tende a ser frequente. Isso foi observado, por exemplo, em uma das obras visitadas, que estava com um dos dois elevadores de transporte de material quebrado, o que comprometia um dos fluxos do processo.

A causa mais grave no sistema PCML foi a 17 (confiabilidade de equipamentos/ferramentas), algo peculiar em relação aos demais. Esse resultado pode ser consequência da mecanização presente nas obras desse sistema construtivo, que aumenta a dependência com as falhas de equipamentos e ferramentas. Outra observação relevante é que metade das oito causas desse sistema está ligada à categoria de pré-requisito do trabalho: 3 (retrabalho devido à qualidade anterior), 4 (baixa qualidade do trabalho anterior), 2 (conclusão dos trabalhos prévios) e 1 (autorização para iniciar o trabalho).

Para Manzione (2007), a industrialização do sistema PCML vai além da forma prática e ágil como são executadas as paredes de concreto; ou seja, a exigência de diminuição do tempo de ciclo estende-se para outros serviços, solicitando maior mecanização do processo e gerenciamento mais eficiente.

\section{Análise dos potenciais riscos da variabilidade associados aos sistemas}

Os gráficos referentes aos sistemas construtivos, obtidos a partir das variáveis intensidade e frequência, são mostrados na Figura 3. Neles foram desenhadas caixas que representam os quatro níveis de risco, classificando as causas da variabilidade em risco baixo, moderado, alto e extremamente alto, a partir dos resultados da análise de clusters. 
Figura 3 - Gráficos (F x I) com divisão das causas em níveis de risco (Continua...)
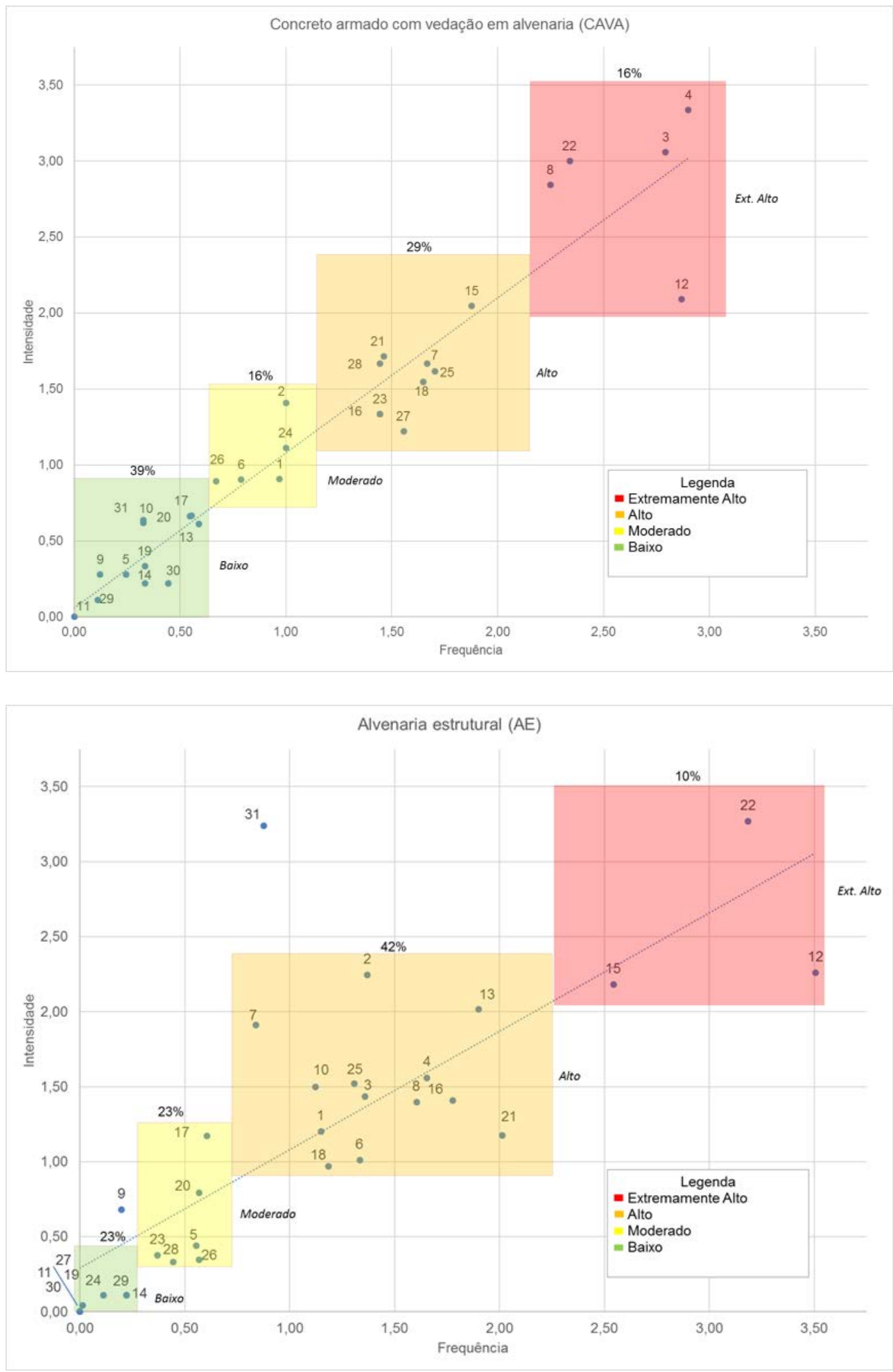


\section{Figura 3 - Gráficos (F x I) com divisão das causas em níveis de risco (continuação)}

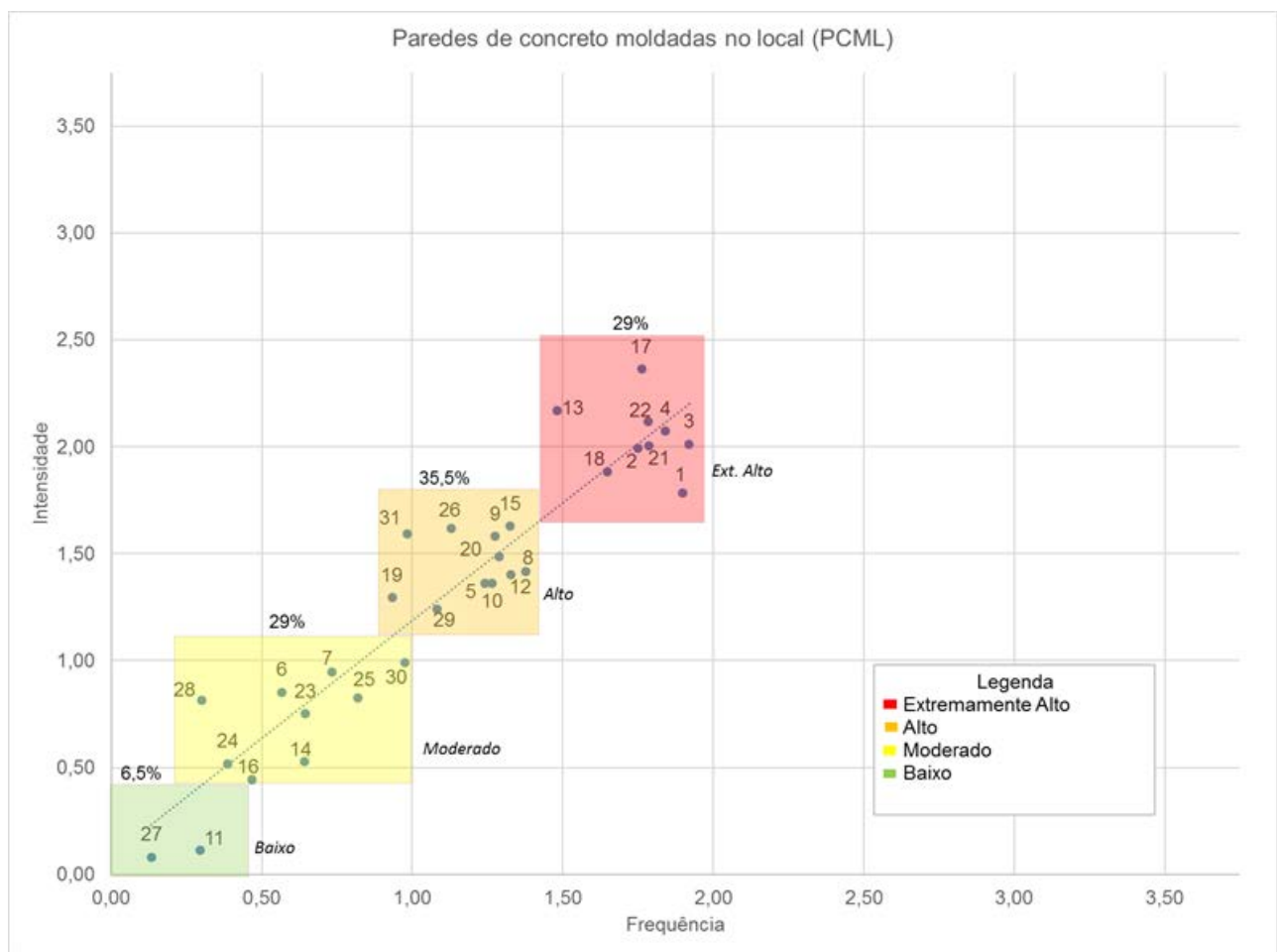

Nota: Legenda:

1 Autorizações para iniciar o trabalho;

2 Conclusão dos trabalhos prévios;

3 Retrabalho;

4 Baixa qualidade do trabalho;

5 Inspeções de trabalhos concluídos;

6 Construtibilidade do projeto;

7 Qualidade dos documentos;

8 Requisitos de controle de qualidade;

9 Complexidade do trabalho;

10 Planej amento da sequência/ método do trabalho;

11 Baixo grau de repetição;

12 Socialização;

13 Absentismo;

14 Pessoas que chegam tarde/ saem mais cedo;

15 Baixa disposição/ motivação;

16 Falta de habilidade dos trabalhadores;

17 Confiabilidade de equipamentos/ ferramentas;

18 Disponibilidade de equipamento/ ferramentas;

19 Capacidade de equipamentos/ ferramentas;

20 Falhas no recebimento dos materiais;

21 Tentativa de solicitação de materiais

22 Recebimento atrasado de materiais;

23 Área de trabalho desordenada/ canteiro congestionado;

24 Leiaute do local de trabalho;

25 Forma de transporte do material;

26 Espera para obter respostas/ orientações;

27 Pouco compromisso por cronograma apertado;

28 Mudanças nas atividades por alterações;

29 Comunicação entre engenheiro e mestre;

30 Comunicação entre mestre e operários; e

31 Impactos climáticos.

Foram encontrados coeficientes de correlação das variáveis (intensidade e frequência) com valores elevados para os dados dos três sistemas construtivos, 0,95, 0,78 e 0,94, respectivamente
CAVA, AE e PCML. Conforme Morettin e Bussab (2012), isso quer dizer que há forte associação entre as variáveis, mostrando uma tendência linear 
crescente, ou seja, quando se aumenta o valor de uma variável, aumenta-se também o valor da outra.

Do ponto de vista da gestão, isso não é um resultado adequado, pois significa que os atrasos mais frequentes são também aqueles que têm maior intensidade, impactando de forma mais acentuada o processo de produção. Essa situação é mais grave no trecho superior direito dos gráficos, onde está localizada a região de risco extremamente alto.

Todas as causas classificadas como de risco extremamente alto estão inclusas no ranking das oito principais causas, o que confirma a importância de analisá-las e de encontrar meios para evitá-las.

A causa 22 (atraso no recebimento de materiais) foi classificada para os três sistemas construtivos como de risco extremamente alto. A causa 12 (socialização) também foi classificada com esse risco, mas somente para os sistemas CAVA e AE, assim como as causas 4 (baixa qualidade do trabalho anterior) e 3 (retrabalho) foram classificadas como de risco extremamente alto somente para os sistemas CAVA e PCML.

A causa 31 (impactos climáticos) comportou-se como um outlier no gráfico do sistema $\mathrm{AE}$, não sendo possível enquadrá-la em um dos níveis de risco. Ela não manteve o padrão da correlação entre as variáveis, mostrando intensidade alta para uma frequência relativamente baixa. Russel (2013) trata da dificuldade encontrada em classificar esses fatores que apresentam baixa frequência e alta intensidade. O autor cita a teoria do Cisne Negro de Taleb, que retrata os impactos desse tipo de situação no processo da construção. Segundo essa teoria, os planejadores têm dificuldades em minorar os efeitos dos raros, porém graves, efeitos das incertezas.
A partir das análises do fator de atraso e da classificação de riscos, são apresentadas duas situações distintas. A Tabela 4 detalha a porcentagem de causas classificadas por nível de risco, o que auxilia na discussão.

A primeira análise, através do fator de atraso (Tabela 2), observa que a soma do fator de atraso (SFA) do sistema CAVA foi a maior $(47,02)$, seguido pelo sistema AE $(38,71)$ e PCML $(29,28)$. Isso sugere que essas causas tenham impacto menor na variabilidade dos processos para o sistema de paredes de concreto do que para os demais.

A segunda análise, através da classificação de riscos (Tabela 4), mostra que há maior número de causas classificadas como de risco alto e extremamente alto para o sistema PCML (64\%), seguido pelos sistemas AE (52\%) e CAVA (45\%). Esse resultado sugere que houve aumento da exposição do sistema de paredes de concreto a causas que apresentam riscos mais elevados.

O gráfico da Figura 4 traz a relação entre as análises realizadas nesta pesquisa, comparando os sistemas construtivos através das somas do fator de atraso (SFA) (Tabela 2) (linha pontilhada), da quantidade de ciclos principais (Figura 1) (linha tracejada) e da porcentagem das causas classificadas nos dois níveis de risco mais altos (Tabela 4) (linha contínua).

Sugere-se então que, com a diminuição do número de ciclos (característica de sistemas mais industrializados), há diminuição do impacto da variabilidade. Porém, de forma contrária, há aumento da exposição do sistema a causas que apresentam riscos mais elevados.

Tabela 4 - Formação dos níveis de risco

\begin{tabular}{c|c|c|c|c}
\hline \multirow{2}{*}{ Sistema } & \multicolumn{4}{|c}{ Níveis de Risco } \\
\cline { 2 - 5 } & Baixo (B) & $\begin{array}{c}\text { Moderado } \\
\text { (M) }\end{array}$ & Alto (A) & $\begin{array}{c}\text { Extrema- } \\
\text { mente Alto } \\
\text { (E A) }\end{array}$ \\
\hline \multirow{2}{*}{ CAVA } & $12(39 \%)$ & $5(16) \%$ & $9(29 \%)$ & $5(16 \%)$ \\
\cline { 2 - 5 } & \multicolumn{2}{|c|}{$B+M=17(55 \%)$} & $A+E A=\mathbf{1 4}(\mathbf{4 5 \% )}$ \\
\hline \multirow{2}{*}{ AE } & $7(23 \%)$ & $7(23 \%)$ & $13(42 \%)$ & $3(10 \%)$ \\
\cline { 2 - 5 } & \multicolumn{2}{|c|}{$B+M=14(46 \%)$} & $A+E A=\mathbf{1 6}(52 \%)$ \\
\hline \multirow{2}{*}{ PCML } & $2(6 \%)$ & $9(30 \%)$ & $11(35 \%)$ & $9(29 \%)$ \\
\cline { 2 - 5 } & \multicolumn{2}{|c|}{$B+M=11(36 \%)$} & $A+E A=20(64 \%)$ \\
\hline
\end{tabular}


Figura 4 - Relação entre as análises da variabilidade nos sistemas construtivos

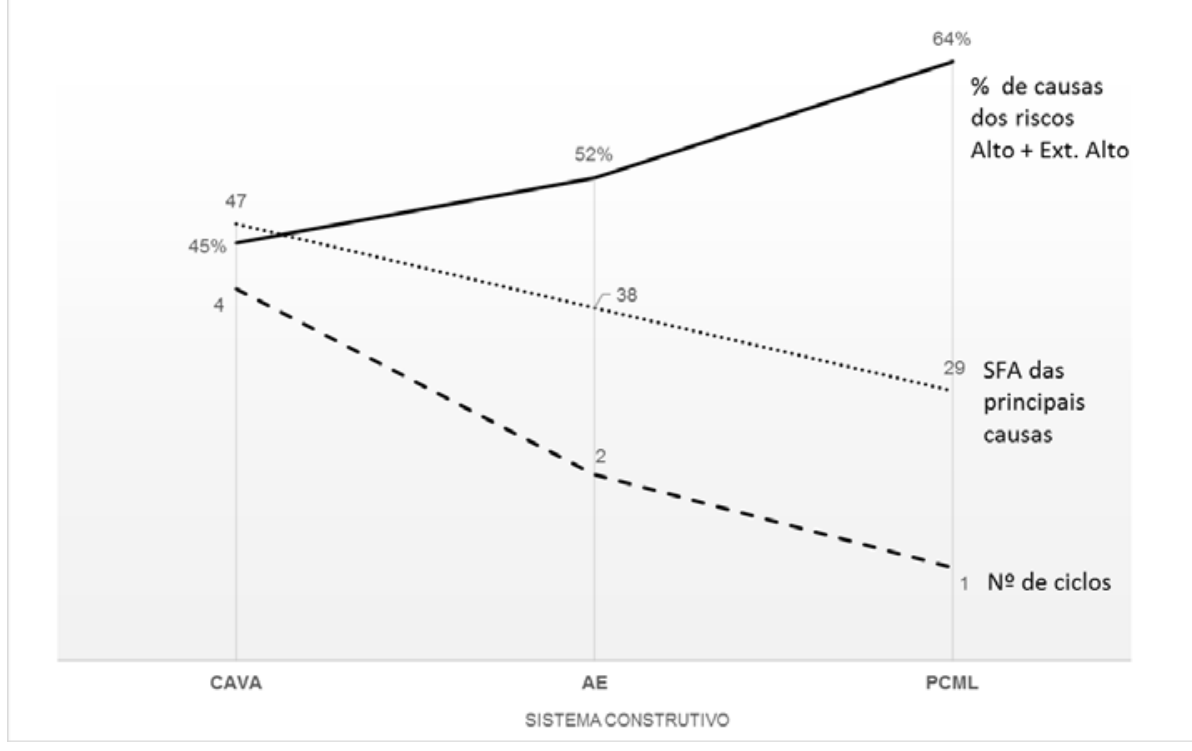

Uma peculiaridade que não foi discutida neste trabalho são as diferentes visões dos níveis hierárquicos quanto às causas da variabilidade. Essa discussão pode ser encontrada em Cruz (2017), em que os resultados sugerem diferenças significativas entre as visões dos engenheiros e operários e dos mestres e operários, porém com semelhanças entre engenheiros e mestres. Concluiu-se naquele trabalho que, à medida que se aumenta o nível hierárquico, aumenta-se também o reconhecimento dessas causas na geração da variabilidade.

\section{Conclusões}

A metodologia aplicada mostrou-se adequada à investigação da hipótese inicial da pesquisa. Os estudos de caso múltiplos, aliados às demais ferramentas empregadas, permitiram coletar os principais dados, além de possibilitar o contato com a realidade dos diversos sistemas construtivos.

O questionário mostrou-se eficiente durante as entrevistas, porém se deve ressaltar que sua aplicação foi presencial, o que possibilitou o saneamento de dúvidas e desvios de interpretação por parte dos respondentes. Sugere-se que, caso essa ferramenta seja aplicada a distância, seja feita uma explicação mais detalhada dos itens, inclusive com exemplos práticos.

A identificação das principais causas para cada um dos sistemas construtivos possibilitou a criação de um ranking de oito causas para cada um deles através do cálculo do fator de atraso. A análise de clusters possibilitou o agrupamento das causas em níveis de riscos, que foram apresentados juntamente com os gráficos para cada um dos sistemas. Todas as causas classificadas como de risco extremamente alto estavam inclusas no ranking das principais causas dos respectivos sistemas construtivos.

As principais causas para o sistema CAVA foram baixa qualidade do trabalho; retrabalho; atraso dos materiais; requisitos de qualidade; e socialização. As três causas mais críticas são comumente conhecidas no ambiente da construção, apesar dos avanços tecnológicos e melhorias no processo de gestão. A presença da causa 25 (forma de transporte dos materiais) no ranking refletiu uma situação comum desse sistema construtivo, que, mesmo tendo maior parcela de movimentação vertical, costuma ter problemas de eficiência nos meios de transporte.

Quanto ao sistema AE, destacaram-se as quatro causas da categoria mão de obra que foram indicadas entre as oito do ranking, assemelhando-se com os resultados de outros autores. Isso pode indicar que haja pouco alinhamento entre os objetivos dos trabalhadores com os de suas obras, acarretando na diminuição da produtividade e da qualidade dos trabalhos.

O sistema PCML apresentou diferença significativa do sistema CAVA através da análise dos dados pelo teste $\mathrm{t}$ de Student, sugerindo que a variabilidade impacta menos esse sistema. Porém, foi aquele que mais apresentou causas classificadas nos níveis alto e extremamente alto, sugerindo que este é mais suscetível a ocorrências de variabilidades no processo. Isso pode ser explicado por sua agilidade, que o fragiliza em relação aos impactos da variabilidade no tempo de execução dos processos.

A análise dos coeficientes de correlação entre as variáveis frequência e intensidade sugeriu uma 
relação inadequada entre as variáveis sob o ponto de vista da gestão.

Conclui-se que a variabilidade do tempo de execução dos processos é um tema complexo e ainda pouco explorado. De fato, os sistemas construtivos podem influenciar no impacto dessa variabilidade. A partir do momento em que esses se industrializam, podem se tornar mais suscetíveis à ocorrência de variabilidade e a seus riscos, porém os resultados deste trabalho sugerem que o impacto pode ocorrer de forma mais amena em relação a sistemas com menor grau de industrialização.

\section{Referências}

COUTO, J. P. Influência dos Atrasos na Competitividade da Indústria de Construção Portuguesa: inquérito nacional sobre o incumprimento dos prazos. In: ENCONTRO NACIONAL SOBRE QUALIDADE E INOVAÇÃO NA CONSTRIÇÃO, 2006, Lisboa, Portugal, 2006. Proceedings... Lisboa: LNEC, 2006.

CRUZ. H. M. Análise das Causas da Variabilidade do Tempo de Execução dos Processos em Diferentes Sistemas Construtivos. São Cristóvão, 2017. 150 f. Dissertação (Mestrado em Engenharia Civil) - Programa de PósGraduação em Engenharia Civil, Universidade Federal de Sergipe, São Cristóvão, 2017.

DE FILIPPI, G. A.; MELHADO, S. B. Um Estudo Sobre as Causas de Atrasos de Obras de Empreendimentos Imobiliários na Região Metropolitana de São Paulo. Ambiente Construído, Porto Alegre, v. 15, n. 3, p. 161-173, jul./set. 2015.

DE MORI, L. M.; JUNGLES, A. E. Impacto de Interrupções no Processo de Produção de Alvenaria Estrutural Sobre a Produtividade do Trabalho. In: ENCONTRO TECNOLÓGICO DA ENGENHARIA CIVIL E ARQUITETURA, 5., Maringá, 2005. Anais... Maringá, 2005.

FAZINGA, W. R.; SAFFARO, F. A.; SANTANA, V. A. Repercussão de Decisões Gerenciais no Prazo de Execução de Empreendimentos da Construção Civil. In: ENCONTRO NACIONAL DE TECNOLOGIA DO AMBIENTE CONSTRUÍDO, 16., São Paulo, 2016. Anais... São Paulo: ANTAC, 2016.

FORMOSO, C. T. Lean Construction: princípios básicos e exemplos. Construção Mercado: custos, suprimentos, planejamento e controle de obras. Porto Alegre, v. 15, p. 50-58, 2002.

GIL, A. C. Métodos e Técnicas de Pesquisa Social. 5. ed. São Paulo: Atlas, 1999.
GONZÁLEZ, P. et al. Analysis of Causes of Delay and Time Performance in Construction Projects.

Journal of Construction Engineering and Management, v. 140, n. 1, p. 1-9, 2014.

HAJIFATHALIAN, K. Effects of Working Strategy and Duration Variance on Productivity and Work in Process: a simulationbased investigation and Oops Game: Cost-benefits tradeoff analysis of reliable planning for construction activities. Raleigh, 2011. 106 f. Dissertation (Master of Science of Civil Engineering) - Graduate Faculty of North Carolina State University, Raleigh, 2011.

HOPP, W. J.; SPEARMAN, M.L. Factory

Physics: foundations of manufacturing management. Boston: Irwin Mc Graw-Hill, 1996.

KOSKELA, L. An Exploration Towards a Production Theory and Its Application to Construction. Espoo, 2000. 296 f. Thesis (Doctor) - Technical Research Centre of Finland, Espoo, 2000.

KOSKELA, L. Making-Do: the eight category of waste. In: ANNUAL CONFERENCE ON THE INTERNATIONAL GROUP OF LEAN CONSTRUCTION, 12., Elsinore, 2004. Proceedings... Denmark, 2004.

MAIA, A. T.; IAROZINSKI NETO, A. Quais as Principais Características Organizacionais das Empresas dos Diferentes Segmentos da Construção Civil? Ambiente Construído, Porto Alegre, v. 16, n. 3, p. 197-215, jul./set. 2016.

MANZIONE, L. Projeto e Execução de Alvenaria Estrutural. 2. ed. São Paulo: O Nome da Rosa, 2007.

MAROCO, J. Análise Estatística: com utilização do SPSS. 3. ed. Lisboa: Sílabo, 2007.

MARTINS, G. A.; THEÓPHILO, C. R. Metodologia da Investigação Científica Para Ciências Sociais Aplicadas. 2. ed. São Paulo: Atlas, 2009.

MAUÉS, L. M. F. et al. Construction Delays: a case study in the Brazilian Amazon. Ambiente Construído, Porto Alegre, v. 17, n. 3, p. 167-181, jul./set. 2017.

MOHAMMAD, N. et al. Investigation on the Causes of Variation Orders in the Construction of Building Project: a study in the state of Selangor, Malaysia. Journal of Building Performance, v. 1, n. 1, p. 73-82, 2010.

MORETTIN, P. A.; BUSSAB, W. O. Estatística Básica. 7. ed. São Paulo: Saraiva, 2012. 
MOTA, B. P.; VIANA, D. D.; ISATTO, E. L. Simulating the Last Planner With System Dynamics. In: ANNUAL CONFERENCE OF THE INTERNATIONAL GROUP FOR LEAN CONSTRUCTION, 18., Haifa, 2010.

Proceedings... Haifa, 2010.

MYDIN, O. M. A. et al. Assessment of Influential Causes of Construction Project Delay in Malaysian Private Housing From Developer's Viewpoint. In: EMERGING TECHNOLOGY FOR SUSTAINABLE DEVELOPMENT CONGRESS, Bangi, 2014. Proceedings... Bangi, 2014.

OLADAPO, A. A. A Quantitative Assessment of the Cost and Time Impact of Variation Orders on Construction Projects. Journal of Engineering Design and Technology, v. 5, n. 1, p. 35-48, 2007.

PATEL, T.; RATHOD, H.; SHARMA, D. Comparison Analysis of Parameters Affecting Material Procurement in Construction Industry by RII and IMPI Methods. International Journal of Scientific Development and Research, v. 1, n. 5, p. 157-162, 2016.

PAWAR, S. P.; BAJAD, M. N.; SHINDE, R. D. Risk Analysis and Strategic Evaluation of Procurement Process in Construction. International Research Journal of Engineering and Technology, v. 4, n. 6, p. 1892-1898, 2017.

POURROSTAM, T.; ISMAIL, A. Significant Factors Causing and Effects of Delay in Iranian Construction Projects. Australian Journal of Basic and Applied Sciences, v. 5, n. 7, p. 450456, Jul. 2011.

REIS, C. J. L. et al. Identificação das Causas de Atrasos de Obras: um estudo de caso na região metropolitana de Belém. In: ENCONTRO

NACIONAL DE TECNOLOGIA DO AMBIENTE CONSTRUÍDO, 16., São Paulo, 2016. Anais... São Paulo, 2016.

RUSSELL, M. M. Allocation of Time Buffer to Construction Project Task Durations. Raleigh, 2013. 180 f. Dissertation (Doctor of Philosophy) Graduate Faculty of North Carolina State University, Raleigh, 2013.

RUSSELL, M. M. et al. Application of Time Buffers to Construction Project Task Durations. Journal of Construction Engineering and Management, v. 139, n. 10, 2013.
SAMARTINI, A. L. S. Comparação Entre Métodos de Mensuração da Importância de Atributos em Produtos e Serviços. São Paulo: GV Pesquisa, 2006.

SAMBASIVAN, M.; SOON, Y. W. Causes and Effects of Delays in Malaysian Construction Industry. International Journal of Project Management, v. 25, p. 517-526, 2007.

SANTOS, A. dos; FORMOSO, C. T.; TOOKEY, F. E. Expanding the Meaning of Standardization With in Construction Processes. The TQM Magazine, v. 14, n. 1, p. 25-33, 2002.

SANTOS, P. R. R.; SANTOS, D. G. Investigação de Perdas Devido ao Trabalho Inacabado e o Seu Impacto no Tempo de Ciclo dos Processos Construtivos. Ambiente Construído, Porto Alegre, v. 17, n. 2, p. 39-52, abr./jun. 2017.

SHA, M. K. et al. Causes and Effects of Delays in Construction Projects. Journal of Mechanical and Civil Engineering, v. 14, n. 2, p. 52-58, 2017.

TOMMELEIN, I.; RILEY, D. R.; HOWELL, G. A. Parade Game: impact of work flow variability on trade performance. Journal of Construction Engineering and Management, v. 125, n. 5, p. 304-310, 1999.

VASCONCELOS, T. M. N. R. F. Building

Information Model: avaliação do seu potencial como solução para os principais atrasos e desperdícios na construção portuguesa. Lsiboa, 2010. 116 f. Dissertação (Mestrado em Engenharia Civil) - Faculdade de Ciências e Tecnologia, Universidade Nova de Lisboa, Lisboa, 2010.

WAMBEKE, B. W.; HSIANG, S. M.; LIU, M. Causes of Variation in Construction Project Task Starting Times and Duration. Journal of Construction Engineering and Management, v. 137, n. 9, p. 663-677, 2011.

WHEELER, M. A. The Evolution and Application of Technical risk Management Within the United Sates Naval. Monterey, 2002. $174 \mathrm{f}$. Thesis (Master of Science in Product Development) - Naval Postgraduate School, Monterey, 2002.

YIN, R. K. Estudo de Caso: planejamento e métodos. 2. ed. Porto Alegre: Bookman, 2001. 


\section{Herbert Melo Cruz}

Programa de Pós-Graduação em Engenharia Civil | Universidade Federal de Sergipe | Av. Marechal Rondon, s/n, Cidade Universitária, J ardim Rosa Elze | São Cristóvão - SE - Brasil | CEP 49100-000 | Tel.: (79) 2105-6700 Ramal 6704 | E-mail: hmc_014@hotmail.com

\section{Débora de Gois Santos}

Departamento de Engenharia Civil, Centro de Ciências Exatas e Tecnologia | Universidade Federal de Sergipe |

E-mail: deboragois@yahoo.com.br

\section{Ludmilson Abritta Mendes}

Departamento de Engenharia Civil, Centro de Ciências Exatas e Tecnologia | Universidade Federal de Sergipe |

E-mail: Iudmilsonmendes@yahoo.com.br

\section{Revista Ambiente Construído}

Associação Nacional de Tecnologia do Ambiente Construído

Av. Osvaldo Aranha, 99 - 30 andar, Centro

Porto Alegre - RS - Brasil

CEP 90035-190

Telefone: +55 (51) 3308-4084

Fax: +55 (51) 3308-4054

www. seer. ufrgs. br/ ambienteconstruido

E-mail: ambienteconstruido@ufrgs.br 